\title{
Assessment of Farmers Perception to Soil Fertility Management in Kalisha District, Hadiya Zone, Southern Ethiopia
}

\author{
Girma Woldemichael", Abebech Endashaw, Abinet Tadesse, Berhanu Achamo \\ Department of Environmental Science, Wachemo University, Hosana, Ethiopia \\ Email address: \\ girmawolde886@gmail.com (G. Woldemichael) \\ ${ }^{*}$ Corresponding author \\ To cite this article: \\ Girma Woldemichael, Abebech Endashaw, Abinet Tadesse, Berhanu Achamo. Assessment of Farmers Perception to Soil Fertility \\ Management in kalisha District, Hadiya Zone, Southern Ethiopia. American Journal of Theoretical and Applied Statistics. \\ Vol. 9, No. 3, 2020, pp. 47-52. doi: 10.11648/j.ajtas.20200903.13
}

Received: December 5, 2019; Accepted: April 20, 2020; Published: May 14, 2020

\begin{abstract}
Soil is one of the natural resource and under high pressure that is increasing from year to year, resulting in poor fertility. The objective of this study was to assess the attitudes of farmer's perception to soil fertility management practices. In order to achieve these objectives, random sampling methods was used to select respondents in the study area. The data was collected by using field observation, questionnaires and key informant discussion. The collected data were analyzed through descriptive statistics. The survey revealed that the factors that hinder farmers from using improved ways of soil fertility management practices are: labor problem $27.5 \%$, economic problem $20 \%$, lack of awareness and demographic factors $37.5 \%$. In the Kalisha District, there are a number of major indigenous soil fertility management practices (SFMP) that are using by almost all farmers such as using cattle dung, straw, intercropping legumes crops in their farm land and use of enset in homegarden area. In other form, this study showed that, in Kalisha District the attitudes of farmers to soil fertility management is less, due to the awareness gap in society and less interventions of development agents. Therefore the farmers should be aware of soil fertility management practices on both biological and physical measures to restore soil fertility and they have to scale up the indigenous SFMP to maintain the productivity of the soil.
\end{abstract}

Keywords: Farmers' Perception, Indigenous Knowledge, Poor Farming Practices

\section{Introduction}

Soil is one of the natural resource under high pressure and this is increasing from year to year, resulting in poor fertility. As a result, the current and updated information is necessary concerning to soil fertility. The fertility and distribution of this natural resource that were help to identify the management of soil fertility and helps to the community to get proper service in which its livelihood to great extent depend up the existence of fertile soil [1].

The focus on any soil fertility replenishment should be integrated nutrient management involving the applications of leguminous, mulches, agro-forestry, composting as well as technologies that reduce the risks of acidification and Stalinization [2]. The aim of soil management is to maintain the fertility and structure of soil. Highly fertile soil results in high crop yield, good cover and therefore, in condition which minimize the erosive effects of raindrops, runoff and wind. The soil have stable granularly structure which does not breakdown under cultivation and high infiltration capacity. The soil fertility thus can soon as the key to soil conservation [3].

One way achieving and maintaining soil fertility is to apply organic matter. This improves the cohesiveness of the soil, increases its water retention capacity and promotes stable aggregate structure. Organic materials may add as green manures; manures had already under going high degree of fermentation [4]. Most of the studies have indicated the soil erosion and associated decline in soil fertility and organic matter deplete are developing information about major constraints to agricultural production in Ethiopia. It is believed generally, that has been a dramatic decline in the fertility of 
agricultural soil throughout the country as a result of farmers reducing fallow period and low number of animal owned do not provide sufficient manure to fertilize crop land [4].

Specifically, Kalisha district has a potential for agricultural productivity due to the existence of adequate rainfall and fertile soil. However, environmental challenges mainly soil erosion and nutrient depletion and poor farming practices has profound effects on the district. Therefore, this study was designed with the overall objective of assessing the perception of farmers to soil fertility management in Kalisha district, Lemo woreda, Hadiya Zone of Southern Ethiopia.

\section{Methodology}

\subsection{Description of the Study Area}

The study area is located in Lemo Woreda, Hadiya Zone of Southern Ethiopia. Kalisha district is one of the rural Kebeles found in limo woreda. The geographic location of the district is $7^{\circ} 30^{\prime} 30^{\prime \prime} \mathrm{N}, 7^{\circ} 35^{\prime} 30^{\prime \prime} \mathrm{N}$ latitude and $37^{\circ} 48^{\prime} 30^{\prime \prime} \mathrm{E}, 37^{\circ}$ 54' 30" E longitude. Kalisha district is endowed with different types of soil, such as sandy clay soil and different in their colors (black, brown and red), even though the dominate soils are clay soils and silt soils. The soils are fertile and suitable for crop and farming production such as teff, wheat, potato, barley maize, and enset but the district is very sensitive for erosion. The population in the study area is unevenly distributed. Some parts of the district are sparsely populated, while the distribution of settlement is mainly based on physical features of the area that is mostly up and dawns, which easily affected by runoff in rainy season. The elevation range of the study area is from 2140 up to 2380 meter above sea level and the district is categorized under tropical climate as humid region. The annual mean average temperature of the district is $14^{\circ} \mathrm{C}$. Agriculture is the main economic base of the community in the district that is an agro-forestry system based practice.

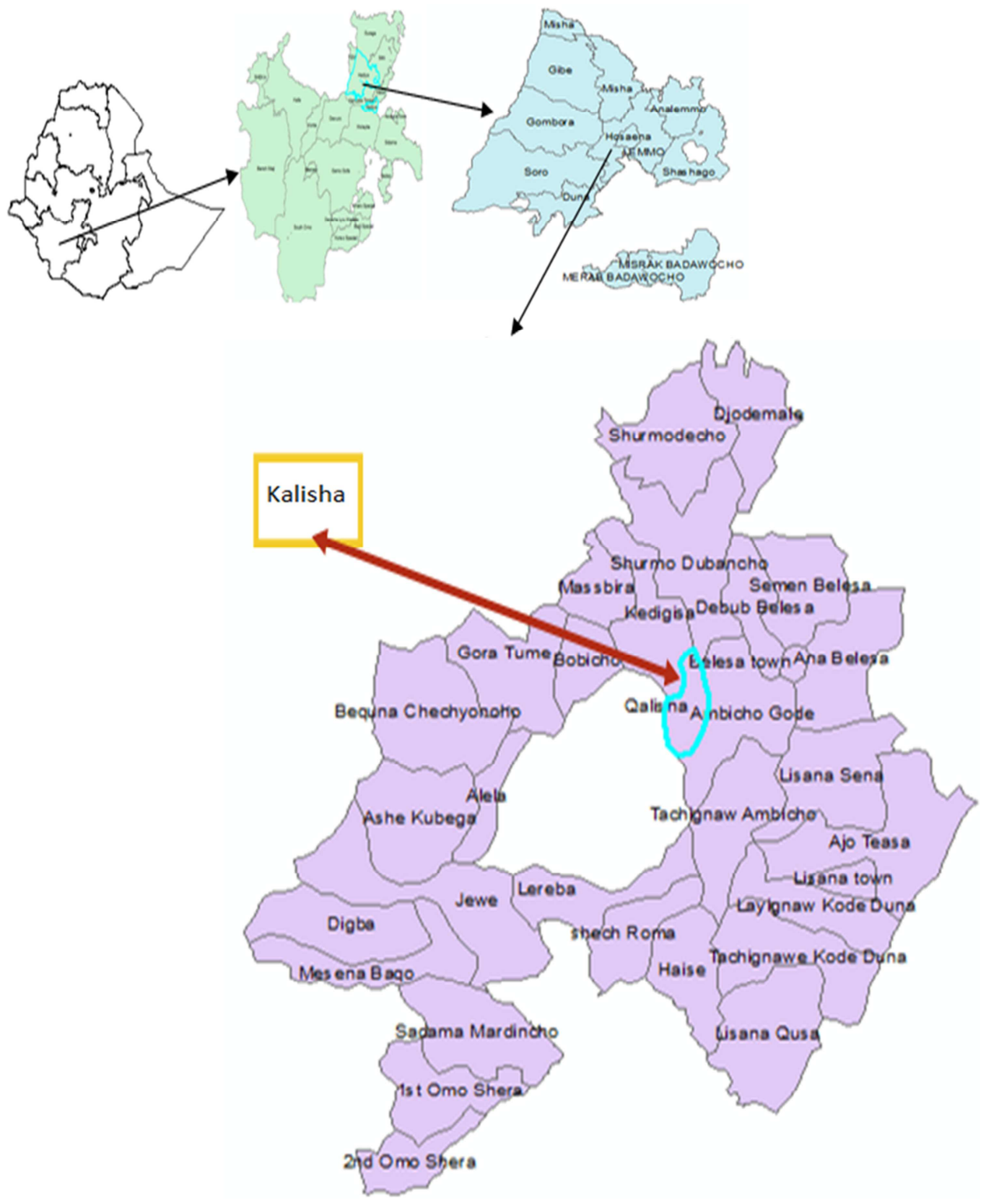

Figure 1. Map of the Klisha district. 


\subsection{Data Collection}

All data concerning the study was collected from both primary and secondary sources; primary data was collected through personal interviews with respondents using questionnaire. Secondary data was collected from various published and unpublished materials such as research paper, reports and relevant documents of governmental offices of the study area.

\subsection{Sampling Techniques and Sample Size}

The respondents were taken by using simple random techniques, because of different experience and knowledge assessment on soil fertility management. In kalisha district 404 households are exist. From this 40 households were taken for data collection. The sample size was determined by the following formula, which was developed by [5].

$$
n=\frac{N}{1+N(e) 2}
$$

Where, $\mathrm{n}=$ sample size. $\mathrm{N}=$ total population. $\mathrm{e}=$ sample error

\subsection{Data Analysis}

Descriptive methods were used to analyse the collected data in the form of statements, percentages and tables that was obtained through questionnaire, interviews and field observation methods about assessment on perception of farmers towards soil fertility management.

\section{Result and Discussion}

\subsection{Socio-economic Characteristics of the Population}

Demographic factors households such as age, sex, and marital status affect the managements of soil fertility. Age can plays a significant role in soil fertility management activities. The survey revealed that in the study area the majority of the respondents are youth and yang, they are found in the age ranges between 17-32 (40\%) and 33-47 $(37.5 \%)$ (Table 1$)$. They are highly productive in soil fertility improvement; whereas the older households are less productive. This is similar with [6] study in which young people are more productive in soil fertility management practices.

Sex is other demographic variables of respondents that determine either female or men are more participated in soil fertility management practices. In the study area, males are more participated in soil fertility management practices. This is agreed with [7]; in this study found that more men's are participated than women's. In the study area $72.5 \%$ of the respondents were males and the rest $27.5 \%$ of the respondent were females (Table 1).

Knowing about marital status of respondents, whether they are married, single, divorced or widowed helps to identify whether there is labor problem or not to participate in soil fertility improvement. Farmer who is married can easily improve their soil fertility due to there is availability of labor. [8] Confirmed that the married people are more participated in soil fertility management practices than others. In the study area $70 \%$ of the respondents are married (Table 1 ).

Number of individuals in household is an important variable considered in soil fertility management as it determines the availability of amount of labor. As the respondents revealed that labor is the major problem in the study area that hinders farmers from using soil fertility management practices: such as composts and terraces. The results are consistent with the assertions that size of household is the major constraints to the adoptions of soil fertility management practices [9]. In the study area, $40 \%$ of the respondents have small number of household, $37.5 \%$ of the respondents have a household between 3-6 and $22.5 \%$ the respondents have a household number greater than six (Table 1).

Educational level of the community is one of the determining factors for managements of soil fertility. In the study area, most of the respondents are literate between the ranges of grade 1-8 or primary school and they aware about soil fertility management practices (Table 1).

Knowing about the source of income of the respondents helps to determine whether the respondents produce cash crops, subsistence production or both. Income is one of the factors that hinder farmers from using soil fertility practice: such as inorganic fertilizer. This is in line with the studies [10] which found that income is a major factor to the adoptions of soil fertility management practices.

In the study area, $45 \%$ of the respondents replied that the main source of income for the peoples are production of cash crops and subsistence production like that of teff, wheat, enset, $35 \%$ of the respondents have been producing only for subsistence production includes enset, maize and others, $15 \%$ of the respondents produced only cash crops that includes teff, and fruits, and 5\% of the respondents are government employers (Table, 1).

Table 1. Socio- economic descriptions of respondents.

\begin{tabular}{llll}
\hline Variables & Response & Frequency & Percent \\
\hline \multirow{4}{*}{ Household size } & $1-3$ & 16 & 40 \\
& $4-6$ & 15 & 37.5 \\
& $>6$ & 9 & 22.5 \\
& Illiterate & 10 & 25 \\
& Only write and read & 6 & 15 \\
& Grade 1-8 & 15 & 37.5 \\
Educational level & Grade 9-10 & 4 & 10 \\
& Grade 11-12 & 1 & 2.5 \\
& diploma & 2 & 5 \\
& degree & 4 & 10 \\
& Cash crop & 6 & 15 \\
& Subsistence production & 14 & 35 \\
& Both subsistence and & 18 & 45 \\
Livelihood & cash crop production & & 5 \\
& Government employee & 2 & 40 \\
& $17-32$ & 16 & 37.5 \\
& 33-47 & 15 & 10 \\
\hline Age & $48-61$ & 4 & 7.5 \\
\hline
\end{tabular}




\begin{tabular}{llll}
\hline Variables & Response & Frequency & Percent \\
\hline \multirow{4}{*}{ sex } & $>76$ & 2 & 5 \\
& Male & 29 & 72.5 \\
\multirow{3}{*}{ Marital status } & female & 11 & 27.5 \\
& single & 6 & 15 \\
& Married & 28 & 70 \\
& divorce & 6 & 15 \\
\hline
\end{tabular}

Table 2. Soil management practice in kalisha district.

\begin{tabular}{llll}
\hline Variables & Response & Frequency & Percentage \\
\hline & Organic fertilizer & 3 & 7.5 \\
Soil fertility & Inorganic fertilizer & 5 & 12.5 \\
management & Animal dung & 8 & 20 \\
practices & Terracing & 9 & 25 \\
& Intercropping & 4 & 10 \\
& Others & 11 & 27.5 \\
Farmers & Low & 16 & 40 \\
perception & Medium & 11 & 27.5 \\
& High & 13 & 32.5 \\
\hline
\end{tabular}

\subsection{Soil Fertility Management Practices in Kalisha District}

This finding revealed that the majority of the respondents' uses soil fertility management practices in kalisha district such as fanyajuu, soil bund, mixed cropping where as organic fertilizer and intercropping practices had not been well practiced due to lack of awareness, problems of labor and capital to apply the practices (Table 2). There are a number of soil fertility management practices that are important to improve the fertility of soils such as organic fertilizer, inorganic fertilizer, animal dung, terracing, intercropping and others [3].

In the study area, there are a number of indigenous soil fertility management practices. All the respondents replied that there are indigenous SFM practices such as dung, straw; intercropping legumes crops in their farm land and use of enset in homegarden area are some of the major soil management practices carried out by the local farmers. Therefore, Indigenous soil fertility management practices are very important to improve soil fertility and increasing of agricultural productivity [11].

\subsection{The Hindering Factors of Farmers from Using Improved Ways of soil Fertility Management in Kalisha District}

The major problem that significantly hinders farmers from using improved ways of soil fertility management practice in kalisha district is labor problem (37.5\%) (Figure 2). This is because of an inappropriate time arrangement and loading of extra house work. The second problem that is identified during the finding is lack of awareness because some of farmers were not participate actively and insufficient trainings of farmers by professionals, this covers $27.5 \%$ of respondents of farmers. The other problem is economic factor $20 \%$ of respondents mainly because of absence of credit and other materials from the government to apply or build SWC practices to improve soil fertility (Figure 2). There were also other factors that are forwarded by respondent like sickness, age factor, sex factor and other social and cultural factors that hinders farmers from using SFM practice. This is consistent with the previous study [8] found labor problem; economic problem and lack of awareness are major factors that hinder farmers from performing soil fertility management practices. According to the respondents in the study area, the perceptions of the farmers to wards to using of SFM practices were low (40\%) (Table 2). This is because lack of awareness about the management practices.

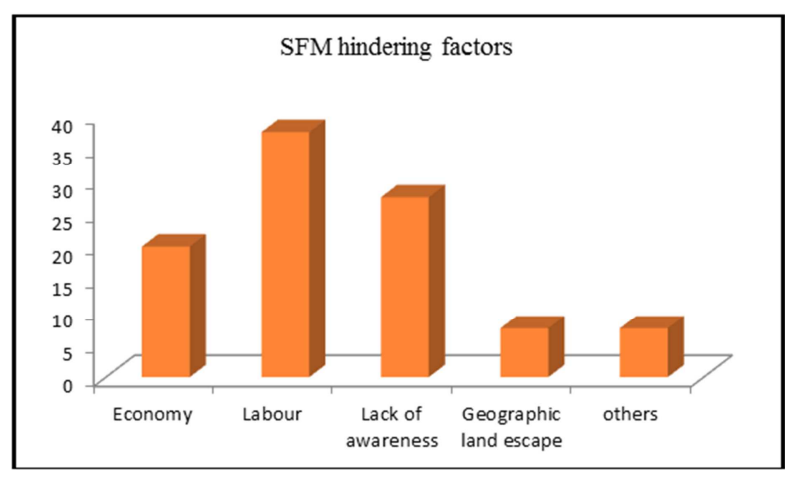

Figure 2. Soil fertility management (SFM) hindering factors.

Cause of SF loss

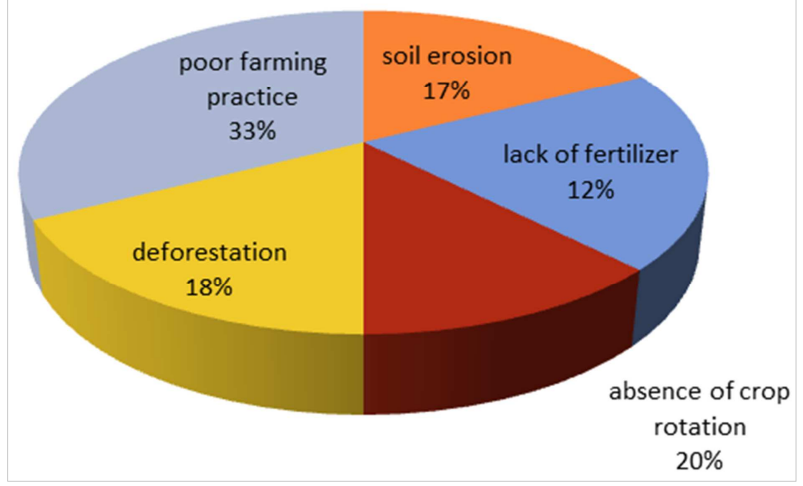

Figure 3. Causes of soil fertility loss (SF).

\subsection{Cause of Soil Fertility Loss in the Study Area}

One of the major cause for soil fertility loss in the study area that identified by this research is soil erosion which is mainly caused by rain fall and the types of erosion are sheet erosion and splash erosion and in some parts of the study area, there is gully formation. The $17.5 \%$ of the respondents revealed that there is soil erosion in their farm land (Figure 3). [4] Confirmed that soil erosion is one of the major causes of soil fertility loss.

In other hand, most of the farmers in kalisha district had not been aware about good farming practices and they uses traditional farming practices. According to [12], poor farming practices are the major anthropogenic causes of soil fertility. This is because of insufficient training and farmer poor participation in the training. In similar way, some of the kalisha district farmers were used traditional system of farming activities which leads to the reduction of soil fertility 
from time to time.

Also most of the farmers had not prepared compost in their homegarden area as well as in their farm land because of lack of awareness and labor problem. Preparation of compost is not adopted in the study area. This is because as the respondents say, there is no professional who gives awareness on how to prepare the compost. Instead of compost or organic fertilizer, the farmers have been using commercial fertilizer for their land which is found far from their houses and they have not been used this type of fertilizer for their homegarden. The reason why peoples use this commercial fertilizer is due to its simplicity to apply and doesn't require more labor. Lack organic fertilizer is another cause of soil fertility losses [3]. This survey revealed that deforestation is one of the causes of soil fertility losses in the study area due to the transformation of agroforestry systems in to shifting cultivation.

Moreover, the respondents identified that the absence of crop rotation is the prominent cause of soil fertility losses in the study area therefore most of the farmers are mainly depend on only production of enset in their homegarden area and productions of teff in farness of their home (Figure 3). Crop rotation is one of the agronomic measures of soil fertility management practices and when there is no crop rotation in the farm land the soil fertility can be declined [13].

The different kinds of poor farming practice have been observed in the study area such as poor tillage and plowing of their farm land in inappropriate time. Poor farming practices are anthropogenic factors that cause the declines of soil fertility [2].

\subsection{Farmer's Perception in the Uses of Plants Residues to Manage Soil Fertility in the Study Area}

In this study, $92.5 \%$ of the respondents in Kalisha district revealed that they leave plant residues on farm and $7.5 \%$ had not leave plant residues on farm and the farmers had different perceptions towards the importance of plant residues. In this case, some of the respondents have assumed that leaving plant residue on farm is important for both as a nutrient and soil erosion reduction, and the others were assumed that plant residue is important as only for improving soil fertility (Table 3). [13] Confirmed that Crop residue is important to increase crop yield, improving soil fertility and protect the soil from erosion caused by rain droplets.

Table 3. Plant residue after harvesting.

\begin{tabular}{|c|c|c|c|}
\hline Variables & Response & Frequency & Percentage \\
\hline \multirow{2}{*}{ Leave Plant residue after harvesting on farm } & Yes & 37 & 92.5 \\
\hline & No & 3 & 7.5 \\
\hline \multirow{3}{*}{ Importance of plant residue } & Soil erosion reduction & 9 & 22.5 \\
\hline & Soil fertility improvement & 14 & 35 \\
\hline & Both & 17 & 42.5 \\
\hline
\end{tabular}

\section{Conclusions and Recommendations}

There are a number of different kinds of soil fertility management practices in the study area, but the attitude of farmers towards soil fertility management is less. This is due to awareness gap in society. Most of the farmers in kalisha distric have been using inorganic fertilizer rather than organic fertilizer due to its simplicity to apply. The indigenous soil fertility management practices in study area are: animal dung, intercropping, and crop residue, these practices are slightly used but these activities are not expanded to all farmers. Due to the existence of labor problem, demographic factor, lack of awareness and economic problem, farmers are facing problem to participate in soil fertility management. Soil erosion, poor farming practices, deforestation and lack of organic fertilizer are identified as the prominent causes of soil fertility losses in the study area.

Based on these findings the following recommendations are forwarded:

1. Creating awareness for the farmers in the study area in order to enhance soil fertility management.

2. Community based soil fertility management practices should be promoted to achieve the reduction of erosion hazards and to ensure soil fertility as a result and improve farmer's livelihood
3. Farmers' indigenous knowledge towards soil fertility management should be also considered in the sustainability of ecology like forest production and land management. Integrating farmers' indigenous knowledge of soil fertility management with the improved soil fertility management practices should be encouraged.

4. Community (farmers) should adapt or aware of soil fertility management practices.

5. The government and farmers should promote appropriate soil and water conservation practices.

\section{References}

[1] Brady Shaw. 1999. Soil and Water conservation.

[2] Mat, B. M. 2005. Soil nutrient management: Overviews of water and soil nutrient managements under smallholders.

[3] Morgan, R. 1996. Soil erosion and conservation. Second edition, long man group work. UK. Paper presented at ICRAF DSO training course.

[4] Eyasu Elias. 2002. Farmers perception of soil fertility change and management.

[5] Yamane, T. 1967. Statistics, an Introductory Analysis, 2nd Edition. New York: Harper and Row. 
[6] Sonii, D. 1992. Adoption dynamics incentives and constraints the case of Agroforestery.

[7] Phiri, D., Franzel, S., Matongoya, P., Jere, I., Kalanga, R., and Phin, S. 2003. Who is using the new technology? The association of wealth status and gender with the planting of improved tree fallowing in Eastern province, Zambia. Agrofo. Syst. (In press).

[8] Muhammed Shanko. 2007. Determinants of participation in soil fertility management practices by smallholder farmers. The case of Gurawa and Haramaya district, East Hararge zone, Oromia, Ethiopia. Msc thesis no. 2007: 44. Haramaya University, Haramaya, Ethiopia.

[9] Frazel, S., Coe. R., Coopeerp., Place, F., and Cherrs, S. 2001. Assessing the adoption potential of Agroforestery Practices in sub Sahara Africa. Agric. Syst. 69: 37-62.
[10] Alene, AD., Manyong, VM., Omanya, G., Mignouna, HD., Bokagna, M. and Odhianbo, G. 2008. Small holder market participation under transaction cost: Maize supply and fertilizer supply in Kenya. Food policy 33: 318-328.

[11] Quinones, M. A., Borlaug, N. E., and Dowsell, C. R. 1998. A fertilizer- based green revolution in Africa. ln: RJ Brush. PA Sanchz and Calhoun (Eds). Replenishing soil fertility in Africa. Pp. 81-95. SSSA Special publication No. 51 Madison. I. USA.

[12] Habarurema, Steiner, K. G. 1997. Classifications of soil suitability by farmer in Rwanda, Geodema. 75: 75-87.

[13] Corbeels, M., Abebe, S., and Mitiku, H. 2000. Farmers' knowledge of soil fertility management strategies in Tigray, Ethiopia. Pp. 12-18. 